\title{
MODERNIZATION OF HISTORIC HEALTHCARE BUILDINGS
}

\author{
JAROSŁAW BĄKOWSKI \\ Gdansk Technical University, Poland
}

\begin{abstract}
The practice of transforming and adapting the existing healthcare facilities to meet the growing demands of modern medicine applies not only to buildings of historical value. Of course, one can set a time point from which hospitals, erected mostly with industrialized technologies, undergo upgrades for better or worse effect. Existing healthcare buildings or facilities, including historic ones, have to be refurbished and adapted to meet the growing demands of modern medicine. Of course, one can set a time point from which hospitals (erected mostly with industrialized technologies) are being transformed or upgraded for better or worse effect. A universal design methodology handling a large number of modern objects can be developed. For older hospitals - especially those coming from the turn of the 19th and 20th century and earlier - the universal methodology must be replaced with individual recognition and approach to specific design problems. From the standpoint of medical technology, the modernization of the historic healthcare facilities (not only hospitals) does not make much sense. Introduction of new medical procedures, subsequent discoveries in the field of medicine and hygiene have been changing hospital environment so much that once some innovative spatial solutions in hospitals are now undesirable. A comparison of the old and the modern operating theatre or bed-wards gives a good idea of the scale and scope of changes that have taken place not only in their functional layouts, but also in their architecture. So, what are the reasons for upholding medical function in these facilities? What methods are needed to achieve the goal? To what extent the historic fabric of buildings can remain? What kind of interventions are acceptable?
\end{abstract}

Keywords: hospital architecture, hospital modernization.

\section{A HOSPITAL AS A PUBLIC SPACE IN HISTORIC CITY}

\subsection{A short history of the hospital}

The history of hospitals is closely connected to the development of medical knowledge and methods of dealing with diseases. The first hospitals were created usually by the places of worship for the reason that treatment was closely associated with belief in supernatural intervention. Not much about the form and size of the buildings designed for such activities can be said. Also, their prevalence was not significant.

The hospital, as an institution, appeared in Europe and the Middle East in the Middle Ages. In organizational terms, the Arabic hospital was significantly superior to its European counterpart, introducing such innovations as the use of specialized bed wards, advanced pharmacy and many other innovations, taking their experience from both the Greco-Roman and the Far East world. The impulse to the institutional approach to hospitality was given by Christianity, with its concept of mercy and care for the weak and the sick. Thus, from the early Middle Ages we could observe the formation of increasingly denser network of institutions dealing with health care. Their duties included caring for the sick, poor and pilgrims who were treated as guests (lat. hospes), hence the name of the hospicium and hospitalis. Shelters, hospitals, hospices, infirmaries were created by the monasteries in which the needy could receive physical and spiritual assistance. At the same time, monasteries functioning in that manner, with their libraries became centres for the development, promotion and exchange of medical knowledge. The Order of the Holy Ghost with numerous 
monasteries-hospitals or multiple Hôtels-Dieu were created. With time care and mercy were limited - there took place a separation of medical and caring function. The next period, the Renaissance, strictly associated medicine with the natural sciences. Then, the eighteenth century brought the idea that the basis of good medicine was to observe the patient at his bedside (gr. $\kappa \lambda i v \eta$ ), so the clinic becomes not only medical, but above all scientific centre. In many countries, this distinction operates until today.

Another factor contributing directly to the development of hospitals was military conflicts. In ancient Rome care centres were built for wounded soldiers and gladiators. Later, with the development of surgery, a military hospital became a permanent element to any army, both as a field or a regular one. A very important event in the history of medicine was the Battle of Solferino, Italy, 1863 as in consequence it initiated the International Committee of the Red Cross. The Committee gave an impulse to the creation of new forms of aid, which with passing time extended not only to the direct victims of battles, but also to victims of natural disasters or epidemics. It contributed to the dissemination of permanent patient care [1].

The development of knowledge about the functioning of the human body, with discoveries of some fundamental principles of anatomy and physiology (modern anatomy - Andreas Vesalius in 1543, blood circulation - William Harvey in 1621, infectious diseases - Louis Pasteur in 1857, antisepsis - Joseph Lister in 1867, radiology - Wilhelm Roentgen in 1895, and many others) made it possible to separate, at least in part, the medicine from the faith. No less important effect of these discoveries were changes in the way of functioning of practical medicine. More and more new methods and medical techniques required not only new tools, but also new spaces at specialized buildings, aimed at practicing and developing these methods. The further and continuous specialization of medicine proceeds which, together with progress in the technology leads even to dehumanization of the entire treatment process. The modern hospital is more a kind of treatment machine than a caring facility (the latter one becomes a separate element of the health care system, in paradoxical way approaching to the original, ancient concept of hospitality). The role of the hospital as a laboratory, or a place of research and observation is also very important.

\subsection{The hospital in a city}

The first locations of hospitals, or rather objects corresponding to the modern ideas of the hospital resulted from the location of their parent structures, mostly temples. The locations were not motivated by any rational premises, on the contrary, places of worship focused and generated the development of adjacent cities together with facilities dedicated to health care. Topography and other local conditions were not always conducive to the building of towns around these centres, so they remained somewhat on the outskirts of cities.

Later, when the principles of establishing and organizing cities become more formalized in Europe, the hospital, even - looking from our perspective - as a small building, could not be placed within the city walls due to their size. Settlement law regulated many aspects of functioning of a medieval city, however, health care issues and ways of solving medical problems were not considered to be important. Only inconveniences arising from functioning of hospitals, fear of the disease and its spread were the respected problems, which were dealt by locating it outside the strict limits of the city. Another important factor influencing the choice of place for the hospital building was the proximity of water and trading routes. Paradoxically, during the nineteenth century, these solutions led to the consolidation of the specifics of the location of the hospital. At the time it was located at some distance from the centre, but also in its close surroundings. A suburban character of the nearest health care facility, such as being surrounded by greenery, sparse urban quarters or a relatively large plot 
was locally preserved. Location outside the exact centre guaranteed relatively good communication with the city and its immediate surroundings. These two factors well etched into the modern ideas of urban planning: the industrial city and the city garden. Unfortunately, both of these ideas excluded the creation of an ideal hospital in a rather crucial point. There was not always a place for therapeutic space in industrial city, strictly subordinated to the idea of movement, availability or efficiency. A green city did not deal well with availability and optimization of space.

\subsection{A tradition of a place as an element of functional continuity}

Mentioned earlier position of the temple, then the hospital can be a successful example of specific tradition of the place. Leaving aside the reasons for the location of these objects, one can observe a strong attachment to the place - often in spite of a radical change of a user, the basic function remains the same. Christian churches arise in place of pagan temples, sacred groves are replaced by monasteries, progressively expanded by hospices and infirmaries.

Looking for a new place for the hospital was and still is a difficult task. Contemporary conditions of location must take into account many more factors than just the medieval fear of illness. Fulfilling all the requirements (spatial, communication, infrastructural, not to mention the financial, social and political) is virtually impossible, so eventually it is a question of optimal, rather than perfect location. One of the fundamental factors of planning a network of healthcare facilities, whether complementary or with various hierarchy of medical procedures, is temporal availability to the hospital. Due to rampant urbanization and increasing population density, the functioning of the new hospitals built in new locations will always require cooperation and complement with the existing hospitals.

\section{THE HOSPITAL AS A CHANGING ENVIRONMENT}

\subsection{Expectations regarding the hospital as a specialized environment}

Hospital is the place intended not only for patients. Obviously, it is a strong simplification the patient is its main and the most sensitive user and the whole activity of the hospital is based on solving his or her health problems. Still, the hospital is additionally a place of work for professionals of different specialties, a troublesome production plant, a significant part of the infrastructure of the city taking an advantage of its resources and aggravating it with dangerous waste.

Basic requirements for hospitals always focused one thing - the fastest and the most effective healing of the patient. Currently, two main trends of constructing the hospital can be observed: one implying filling the hospital with possible resources, technical equipment and apparatus to the maximum extent and providing sufficient space for medical procedures (technologization trend) or one concerning creation of favourable conditions for staying, using non-physical therapies or providing the friendly environment (a humanization trend). As usual, the most successful projects are those respectively combining these two extremes.

How do these considerations relate to the essence of this article? Now, the expansion of the historic building seems to be a good excuse to check the possibility of merging these two approaches, especially in a case of the hospital building. Construction of the hospital from scratch almost absolve us of the obligation to refer to the existing conditions of the cultural environment: the existing building and its surroundings, the problems of adaptation and change of environment, not only in a strictly functional, but also cultural aspect. Freedom in building a new space facing constraints arising only from the functional and technological 
requirements are conducive to creating new, even innovative solutions. Expansion of the hospital, especially historic, brings more challenges: first of all, the principle decision on the extent of change and intervention must be taken. It translates to determine whether its architecture presents such characteristics for which a decision on respecting them is obvious. The main criterion is always the assessment and reference to real cultural and historical values of the building.

\subsection{Factors influencing changes in the hospital}

Each reconstruction, expansion or modernization of the hospital follows a strictly utilitarian assumption - implementations, for which the main condition would be a desire to restore the facade of the times of greatest splendour of the building are not usually met. Purely restoration actions, if performed, are rather an addition to widely established plan of adjustment hospital building to modern needs. However, regardless of the cause and initial conditions, there is a problem of use or adapting existing structure and it is an important part of the design process.

In the case of historic buildings, to achieve the primary objective (an expansion, change or improvement of the way they operate) often complete reconstruction or remodelling of the internal structure is required. Several categories or some elements of the building can be distinguished to cause the greatest difficulties in adapting them to the requirements of the modern hospital. These are mainly:

- Structural system. The construction of complex functional systems that would meet the requirements of the medical technology (with principles of ergonomics and adequate flow of staff and patients inside the hospital or among hospital wards, aseptic requirements, a contradiction of internal communication, ensuring suitable area and many others) is possible when using a modular construction grid that is flexible enough (with correspondingly large spans and repeatability, enabling the design of an universal set of rooms with adequate space and proper conditions of natural illumination) and susceptible to the introduction of special solutions (i.e. open-planned design, dividing spaces with use of light partition walls, which mainly applies to skeletal structural system) [2].

- Installation equipment. Construction of a modern medical environment leads to its being cut off from the influence of external conditions or even to construction of an artificial internal environment. The more complex and more specialized is the environment, the greater is the need for ensuring such health conditions that would not only help, but even allowed to carry out complex medical procedures, regardless of external conditions. This applies not only to specialized installations (installation of medical gases, tele-technical installations and equipment), but above all, ventilation and air conditioning. The latter is an especially important element in terms of modernization and reconstruction of any building. The specificity of ventilation creates at least two problems in the object: the location of large-size equipment and an appropriate method of distribution large-section installations inside the building [2], [3].

- Fire protection and other safety-related issues. Progressive necessity of introducing the various fire protection systems, both active and passive, the need to eliminate some solutions and materials from the structure of the building (at least in the Polish practice) cause these problems to become one of the most important during the adaptation of existing or historical buildings. In the case of buildings of special historical or cultural values a number of derogations from these requirements are permitted; still each case 
should be agreed and get approval of the relevant authorities on the use of alternative solutions. This applies mainly to the size parameter of escape routes (the width of staircases or passages and similar solutions as well as introducing an anti-fire alert systems). Obtaining such a derogation results only in a possibility to reduce an interference in structure of the building, and it does not always allow for the proper solution of functional details.

\subsection{A size of the hospital building - consolidation and steady growth}

All of these factors lead to an observation of two constant tendencies related to the functioning of the hospital: an increase in usable area of the hospital per patient and consolidation, involving organizational and spatial combining smaller facilities in larger ones. Obviously, in addition to functional or technical reasons, such activities have a strong economic base [4], [5].

An operating theatre of the Voivodship hospital in Elbląg (a voivodship is the highest level of territorial division and administration, can be referred as a province) is an example of a solution to the modernization problems of a complex functional unit (Fig. 1). Admittedly

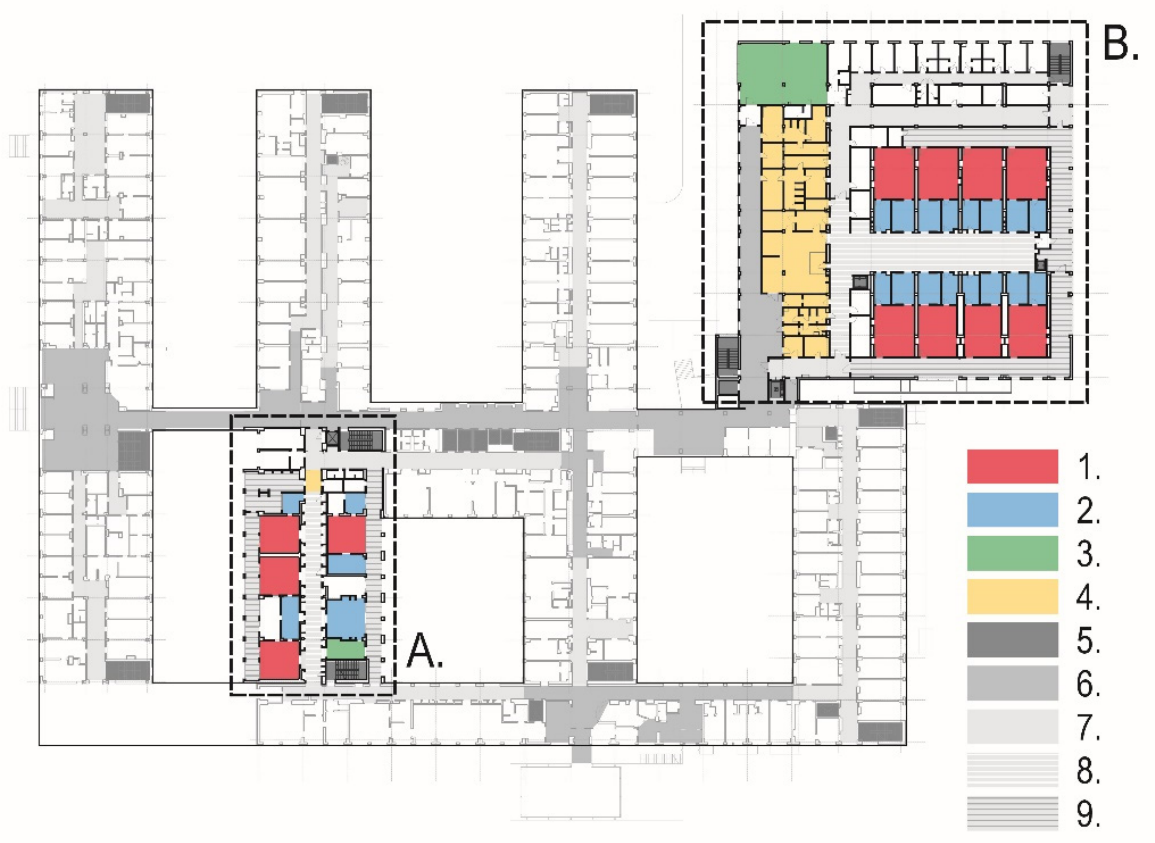

Figure 1: Comparison of the size and the spatial arrangement of the operating theatre. Voivodship hospital in Elbląg, before (A) and after expansion (B). Explanatory figure, a former operating theatre was located on the ground floor, the new one on the 1 st floor. $1=$ operating rooms, 2 = patients and staff preparation rooms, 3 = post-operation rooms, $4=$ patients, staff and material locks, $5=$ staircases and lifts, $6=$ general hospital communication, $7=$ in-wards communication, $8=$ internal clean route, 9 = internal dirty route. Project by. arch. S. Sosak, 2012. 
the hospital is not a historical monument, but its example can demonstrate how modern diagnostic department becomes a part of the existing hospital structure. Basic requirements for the operating theatre refer to two problems: adequate separation of the patients, staff and operational materials routes (with the division on the clean and dirty route) and the size of the rooms. The new operating theatres have now from 43 to $48 \mathrm{~m}^{2}$ (previously 33 to $35 \mathrm{~m}^{2}$ ), and their number increased from 4 to 8 (which is associated with the tendency of modifying hospitals profiles from long-term residential care for short-term diagnostic and treatment facilities). The solution of both these dependencies was not possible within the existing system and (as with many other hospitals) the decision was made to build a new treatment wing, allocating at the old department a bed ward (with far less demands on the technical equipment and more opportunities to use existing functional separation).

\subsection{A function relocating within the hospital building}

In the case of existing, functioning hospitals (without the possibility of excluding them from use, even temporarily) continuity of their work is one of the factors determining the possibilities of functional transformation, and it is a very difficult condition to meet.

It is unacceptable when during construction works a department of the hospital simply ceases its functioning or works on a limited basis. This mainly relates to diagnostic and treatment departments, without which the functioning of other parts becomes impossible. Hence one of the characteristics of modernization is either to carry them on the principle of relocating the department (or ward, with appropriate functional links between departments) or splitting a task into several modernization stages (allowing the department to be left at the original place) [4].

Both approaches to the problem are evident in the hospital in Elblagg: the operating theatre was transferred to the newly-designed wing, and its emergency department is being modernized, left in its original location and dividing the construction tasks into several stages.

\section{THE HOSPITAL ARCHITECTURE}

\subsection{Problems connected to reconstruction and expansion of hospitals}

Hospitals themselves, at least Polish ones, are rarely considered to be monuments of architecture of high rank or quality, but still they constitute a distinguishable and distinctive element of a landscape of the city, creating its history and tradition. They occupy quite a large area of the city: together with their garden complexes, sometimes weighing up to 8 hectares, being rebuilt several times, often losing their original architectural expression, with any extension or reconstruction they carried new spatial and architectural solutions. Unlike public facilities of other features, architecture of hospitals is formed mainly on a basis of functional conditions. The shape of the building to the greatest extent is determined by the operational requirements. For hospitals or hospital units, one can indicate a set of several characteristics that determine the architecture of these objects [4]:

- A size of the building (and its constant increase). A consolidation of small hospitals and gradually transforming them into a larger unit, forced by organizational and economical issues result in a significant increase in the size of the building or the hospital unit. The building rises far above the scale not only its immediate surroundings, but over time it begins to dominate even in the scale of the city. Depending on the rank of the hospital within the health care system it becomes the object of a county (hospital in Kwidzyn Fig. 2) or voivodship level of the health care system (hospitals in Gdańsk and Elbląg). 


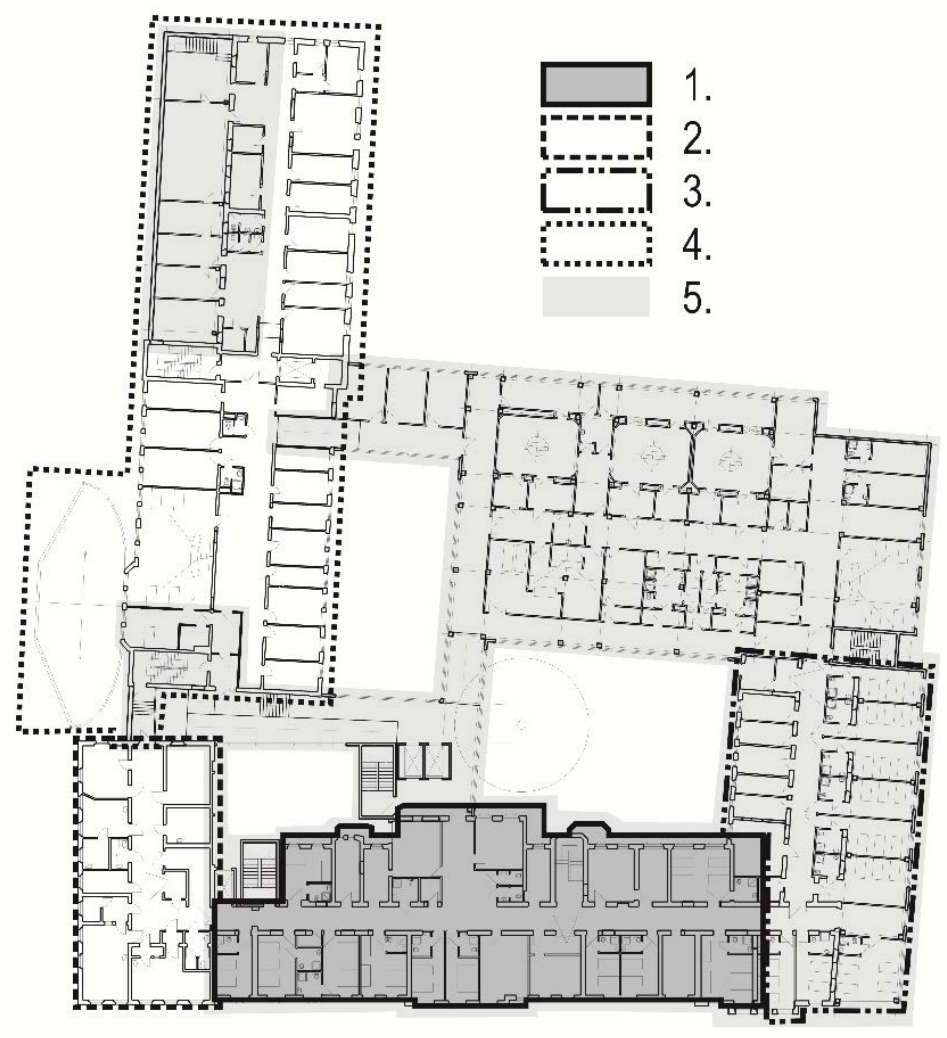

Figure 2: Stages of a hospital development, the county hospital in Kwidzyn. 1st floor layout. The main phases: 1 = original building from the beginning of 20th century, $2=1930$ s extension, $3=1950$ s extension, $4=1960$ s extension, $5=$ planned refurbishment and development, project by arch. J. Bakowski, A. Kohnke, 2014.

- A repeatability of architectural composition. Characteristics of hospital functional systems dictates specific formal solutions for its form and elevation. The vast majority of hospitals are compositions of relatively simple forms, with elevations of uncomplicated articulation and repetitive elements. This repeatability is especially evident in the wings of hospitalization (bed wards) which are in their architectural expression similar to hotel solutions (as both of these functions correspond each other on basic level, this is quite natural).

- A compactness. Apart from few examples of hospitals built as pavilions (i.e. in the form of an assembly of several buildings with a relatively small cubic capacity, arranged at some distance to each other) the requirements of immediate availability of communication between hospital departments cause that the building is a compact composition. The need for quick communication accessibility and comfort of organizing the hospital "under one roof" means even that some of the old pavilion hospitals are expanded to become the one-space object. Clearly, bed wards still may be located more freely, to a greater distance from each other (creating internal atriums or 
more natural garden complexes). Concentration of the "masses" of the building concerns some of the most "technological" parts, related directly to medical activities.

These three factors (plus internal technical conditions) impose a fairly obvious solution: the existing, historic part of the building of the hospital, equipped with the relatively simple but still suitable systems which do not cause too much interference with the structure of the building, can become a classic part of the hospital (its bed ward) [6]. The diagnostics and treatment wards are placed in the newly-designed wing, built from scratch, combined or linked to the old building [7].

\section{CONCLUSIONS: HOSPITAL AS AN ARCHITECTURAL HYBRID}

Of course, one can argue how "historical" architecture is more friendly to a man than the "modern" one. Certainly it is a matter of familiarity with traditional architectural forms, details and materials. So, what are the reasons for upholding medical function in these facilities? What methods are needed to achieve these goals? To what extent the historic fabric of buildings can remain? What kind of interventions are acceptable?

Building architectural space for hospitals on the basis of the aforementioned evidence can help to achieve at least two objectives: to build a modern hospital, susceptible to changes, with a high-level and high-tech diagnostic and treatment centre, backed by its historical buildings forming friendly space tailored to the scale and perception of the patient [8]. The first element can be embedded into the new part of the hospital, built using the latest construction techniques and perfectly suitable to contain any modern medical equipment, but at the same time deliberately designed for use over the relatively short period (the average time of depreciation of medical technology ranges from 20 to 30 years), after which it would be exchanged and replaced by the new spatial layouts. The space closest to the patient, the bed wards, can be left in the old wing of the building, adapted to meet the increased requirements of patient's comfort of stay.

So, what are the architectural approaches to the problem? Of course, there is no single solution, as the problem of modernization and refurbishment of hospitals consists of many issues to be solved. There can be observed at least three different methods for delivering architectural models: the total transformation of the building, ignoring any historical context (county hospital in Malbork, Fig. 3); steady growing of a hospital, adding new values with respect to original building or even refurbishing it (county hospital in Kwidzyn, Figs 2 and 5); adding new elements referring to existing historical values (county hospital in Giżycko, Fig. 4).
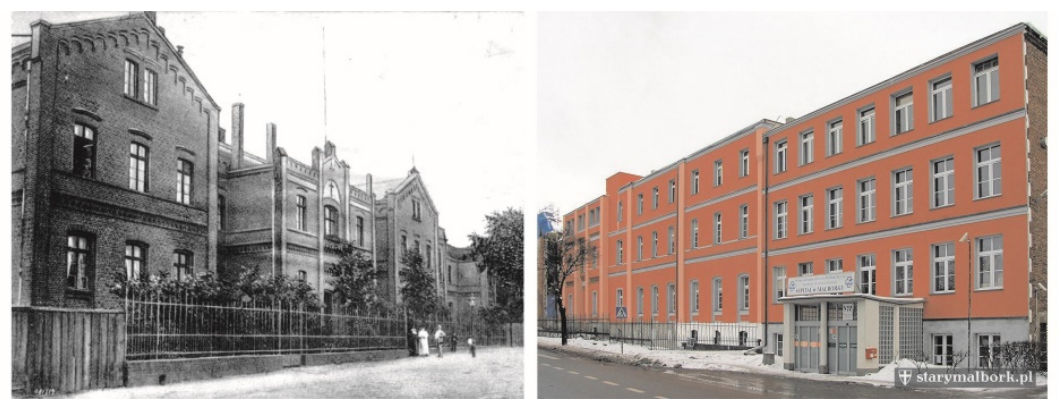

Figure 3: County hospital in Malbork, the original state dating back to the end of XIX century (left) and present, after modernization (right). The example of a total loss of original architectural values. 

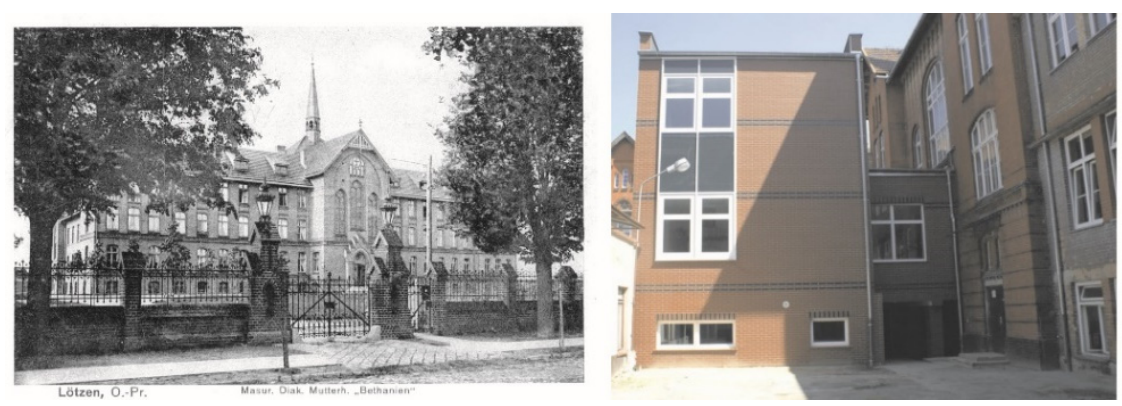

Figure 4: County hospital in Giżycko, the original state dating back to the end of XIX century (left) and present, after modernization (right). Good example of using contemporary forms and materials to maintain historic values of the building.
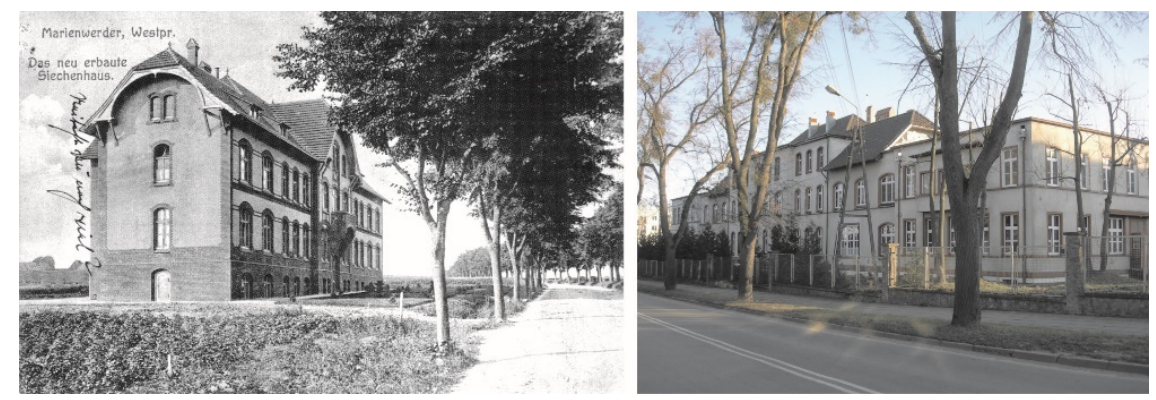

Figure 5: County hospital in Kwidzyn, the state dating back to the beginning of XX century (left) and present (right). Example of a ever-growing hospital, with many extensions.

\section{REFERENCES}

[1] Thompson, J.D. \& Goldin, G., The Hospital: A Social and Architectural History, Yale University Press: London-New Haven, 1975.

[2] Czabański, W., Modernizacja i rozbudowa szpitali ogólnych na wybranych przykładach z województwa gdańskiego, $\mathrm{PhD}$ thesis, Gdańsk University of Technology, 1986.

[3] Ponikło, W., Infrastruktura techniczna szpitala, ABC Wolters Kluwer Business: Warszawa, 2010.

[4] Poplatek, J. \& Bąkowski, J., Problemy modernizacji szpitali. Architektura służby zdrowia. Problematyka projektowania, eds A. Gębczyńska-Janowicz \& R. Idem, Wydawnictwo Politechniki Gdańskiej: Gdańsk, 2015.

[5] Justyńska, E., Doświadczenia przy modernizacji obiektów służby zdrowia, Biuletyn Informacyjny Budownictwa Służby Zdrowia, no. 2(86), Warszawa, pp. 38-52, 1989.

[6] James, W.P. \& Tatton-Brown, W., Hospitals Design and Development, Architectural Press: London, 1986.

[7] Malicka, A., Kształtowanie przestrzeni pacjenta w nowoczesnych obiektach szpitalnych - przykłady szpitali w Europie, AT-Z VII Międzynarodowe Sympozjum: Gliwice, pp. 115-126, 2010.

[8] Verderber, S., Innovations in hospital architecture, Routledge Taylor \& Francis Group: New York, 2010. 